\title{
The central tendency effect in stimulus generalization: Effects of establishing a "preexperimental" frame of reference
}

\author{
ROBERT J. NEWLIN, JAMES P. RODGERS, JAMES F. DICKSON, JR., \\ HARRY STRUB, and DAVID R. THOMAS \\ University of Colorado, Boulder, Colorado 80309
}

\begin{abstract}
An experiment was performed to test the hypothesis that in a voluntary generalization task subjects encode the training stimulus (TS) in relation to the adaptation-level (AL) prevailing at the time of TS presentation. If so, then during a subsequent generalization test the point of maximal generalized responding should bear this same relationship to the AL of the generalization test series. To test this hypothesis, three major groups of subjects $(n=80)$ were given preexposures with dim lights (low preexperimental AL group), bright lights (high preexperimental AL group), or no preexposure (control group). Next, half of each group was exposed to a TS and a subsequent generalization (recognition) test including this brightness and four others. The other half of each group was exposed to the same TS and subsequent generalization stimuli, but their task was to rate the stimuli on a 7-point bright-dim scale. This provided AL measures which could be correlated with generalization performance in the comparable generalization groups. The preexposure condition was successful in producing the expected low or high preexperimental ALs, as reflected in different ratings of the TS when it was presented. Furthermore, these effects persisted throughout testing, as evidenced in ALs (i.e., rating scale midpoints) which reflected the preexposure condition. Finally, the difference between the point of maximal generalized responding and the AL of the generalization test series was highly and significantly correlated with the difference between the original rating of the TS and scale midpoint. This supports the major experimental hypothesis of the study.
\end{abstract}

Thomas and Jones (1962), in a study of voluntary stimulus generalization, found that the location of the training stimulus within the test series had a marked effect on the symmetry of the resulting generalization gradients. Their subjects were given a 60-sec exposure to a $525-\mathrm{nm}$ training stimulus (TS) with instructions to remember the stimulus so that they could identify it during a subsequent wavelength generalization test. The location of the TS in the test series was systematically varied, with the TS being in the center position of the test series for one group and asymmetrical (i.e., displaced from the center) for four other groups. Only with the symmetrical group did a symmetrical generalization gradient (with a peak at the TS) result. For the other groups, the peak was shifted from the TS toward the center of the test series. This finding, which Thomas and Jones called a "central tendency effect," has been replicated many times with different stimulus

This study was conducted at the University of Colorado at Boulder; James F. Dickson and Harry Strub participated while on sabbatical leave from their home institutions, St. Olaf College and the University of Winnipeg, respectively. The research was supported by NIH Research Grant HD-03486 and Training Grant MH-10427 under the direction of David R. Thomas. The paper is respectfully dedicated to the memory of Harry Helson. Requests for reprints should be sent to David R. Thomas, Department of Psychology, University of Colorado, Boulder, Colorado 80309. dimensions, including size-area (Helson \& Avant, 1967), weight (Hébert, Origlio, \& McGuirk, 1972), brightness (Thomas, Strub, \& Dickson, 1974), and line angle (Thomas \& Thomas, 1974).

Capehart, Tempone and Hébert (1969) proposed that the central tendency effect was explicable in terms of an extension of Helson's (1947, 1964) adaptation-level (AL) theory. Capehart et al. view $\mathrm{AL}$ as a stored referent against which all experienced stimuli are judged. It is the subject's subjective representation of a neutral or average value on the continuum in question. The $\mathrm{AL}$ is a dynamic referent, continually subject to change as new stimulus information is processed.

In applying the $\mathrm{AL}$ theory to the analysis of the central tendency effect, Capehart et al. assumed that most experimental situations were sufficiently distinctive that the role of residual stimuli from past experience was negligible in determining the training AL. Thus, with the initial exposure to the TS, the $\mathrm{AL}$ is presumably formed at the value of the $\mathrm{TS}$, the only relevant stimulus experienced in that situation. The instruction to respond on subsequent presentations of the TS presumably establishes the decision rule, "Respond to the prevailing AL value." During generalization testing, the $\mathrm{AL}$ undergoes continual revision with continued exposure to the test stimuli. Thus, with an asymmetrical test series, 
the prevailing AL would shift toward the central value of the test series, and responding would be displaced accordingly.

Consistent with the Capehart et al. model are the observations from the studies cited above that the central tendency shift occurs progressively as testing continues, and the magnitude of shift is a direct function of the degree of asymmetry in the test series.

Capehart et al. point out that the validity of the application of $\mathrm{AL}$ theory to the analysis of stimulus generalization does not depend on the acceptance of any particular mathematical model for a priori prediction of the locus of the AL (e.g., the weighted $\log$ mean). That particular model may apply to some stimulus dimensions and not to others. In the work to be considered in the remainder of this paper, $\mathrm{AL}$ is defined empirically rather than theoretically as the "average" stimulus, as determined in a rating task (cf. Helson, 1964, Chapter 4).

Hébert, Bullock, Levitt, Woodward, and McGuirk (1974) obtained direct evidence for the hypothesized link between AL changes in testing and the central tendency shift. These investigators employed a procedure which permitted them to obtain both a generalization gradient and an $\mathrm{AL}$ measure from individual subjects. After exposure to a lifted weight TS, subjects were exposed to a random series of test weights. During each test stimulus exposure, subjects were required to make two judgments: (1) indicating whether the test weight was the same as or different from the TS, and (2) rating the test weight on a 7-point lightness-heaviness scale. Hébert et al. observed throughout testing that there was a strong tendency for subjects to respond "same" to weights which they judged as " 4 " (the scale midpoint or AL weight) and very little tendency to judge as "4" stimuli responded to as "different." With this procedure, the maximal responding (with "same") and AL were similarly displaced. Thus the evidence from the Hébert et al. study is consistent with the Capehart et al. assertion that the TS is encoded as equivalent to the $\mathrm{AL}$ prevailing at the time of TS exposure. There are two aspects of the Hébert et al. procedure, however, which tend to reduce its applicability. First, it is possible that the subject simply remembered what rating he gave the "same" stimulus or to what rating he said "same," thus artifactually tying the two scales together. Second, the rating procedure was used only in the symmetrical test where displacement of modal responding was slight (for lifted weights, AL has been found to be below the central stimulus; cf. Helson, 1947), and although the amount of displacement was not changed relative to a condition in which the ratings were not given, the number of "same" responses was reduced. This reduction does indicate some nonindependence of performance on the rating and same-different judgment tasks within subjects.

Recently, Thomas et al. (1974) obtained results at variance with one part of the Capehart et al. formulation. In Experiment 1 of the Thomas et al. study, subjects were assigned to one of seven experimental groups, shown a $\operatorname{dim}(0.83 \mathrm{fL})$ white light, followed by exposure to a series of varying intensities. For each group, the range of stimulus values used in generalization testing differed. For all groups, the range of intensities employed consisted of the TS plus several additional stimulus values, all of which were more intense than the TS. Like Hébert et al., Thomas et al. obtained both generalization and AL measures on each trial. On the generalization test trial immediately after exposure of the TS, recognition of the TS was quite accurate. However, contrary to the Capehart et al. formulation, AL was not at the value of the TS, but was somewhat greater than the TS. Furthermore, for each of the seven groups in the Thomas et al. study, maximal responding was to a stimulus of lower intensity than that group's mean $\mathrm{AL}$. The correspondence between (but not equivalence of) $\mathrm{AL}$ and the point of maximal generalized responding was also seen in the systematic changes in these response indices during the course of generalization testing. From the first quarter to the remainder of the generalization test, both $\mathrm{AL}$ and the point of maximal generalized responding shifted upwards. The two measures changed in parallel fashion but remained different throughout.

Although the results of the Thomas et al. study are generally consistent with the assumption of Capehart et al. that stimulus equivalence is defined with reference to the $A L$ value and that $A L$ is affected by the processing of relevant information, the data are at variance with the assumption that AL is initially established at the TS value. Thomas et al. speculated that the reason that their subjects encoded the TS as below their AL was that residual (i.e., preexperimental) factors were influencing their judgments. The TS was "dim" in comparison with lights in the waiting room and others with which the subject would be familiar. Taking this into account, the subject's conception of an "average" brightness would be a more intense value than that of the TS employed by Thomas et al.

Dickson and Strub (cited in Thomas, 1974) manipulated the "preexperimental" AL by showing subjects relatively bright or dim lights prior to the presentation of an intermediate TS. Generalization gradients were then obtained on a series including the TS and four brighter stimuli; all five stimuli were located between the two sets of preexposure stimuli. 
As would be expected if subjects encoded TS in relation to their pre-TS exposure, subjects with the dim preexposure shifted more than subjects with a brighter preexposure. The subjects also rated all stimuli on an 11-point brightness scale. Dim preexposed subjects responded "same" to a stimulus above their calculated $\mathrm{AL}$ and bright preexposed subjects responded "same" to a stimulus below their calculated AL. Again, each subject gave both a "same-different" response and a rating, leaving open the possibility that one judgment affected the other.

The present experiment was designed to replicate and extend the Dickson and Strub finding. Specifically, we tested the hypothesis that subjects encode the TS in relation to the AL prevailing at the time of TS presentation. The hypothesis was tested by manipulating AL prior to presentation of the TS and obtaining AL (rating) and generalization (samedifferent) data from independent groups of subjects. If subjects encode TS in terms of its difference from prevailing $\mathrm{AL}$ (e.g., $\mathrm{TS}=\mathrm{AL} \pm \mathrm{X}$ ), then during a subsequent generalization test the point of maximal generalized responding (i.e., the stimulus value perceived as the TS) should be similarly related to, but not identical to, AL. This hypothesis can be tested with independent groups of subjects on the basis of the reasonable assumption that since the rating groups are exposed to the same stimuli as are the same-different groups, their ALs should be the same as those which would have been obtained from the same-different groups, had it been possible to obtain uncontaminated $\mathrm{AL}$ scores from them.

The two major groups of subjects (rating and same-different) were further subdivided into three groups. One was preexposed to a set of "dim" lights, designed to produce a low "preexperimental" AL. One was preexposed to a set of "bright" lights, designed to produce a high "preexperimental" AL. A third (control) group had no preexposure, in order to assess the effect of true preexperimental AL. Each of these groups was further divided into two subgroups, one with a low TS value and one with a high TS value so as to produce a range of
$\mathrm{TS}=\mathrm{AL} \pm \mathrm{X}$ relationships differing both in magnitude and direction. Normally, a group which has a low (or high) TS value and only higher (or lower) values as test stimuli will show a shift in maximal responding toward the center of the series of test stimuli. In the present case, we predicted that this shift would not necessarily be to a central test value but rather to that test stimulus which bears the same relationship to the test $\mathrm{AL}$ as the TS did to "preexperimental" AL. Finally each group was further divided into male and female subgroups of equal size. Although sex difference was not the focus of this experiment, both Giurintano (1972) and Thomas and Fenner (1978) have reported sex differences in the magnitude of the central tendency shift.

\section{METHOD}

Subjects

The subjects were 120 male and 120 female students enrolled in introductory psychology courses at the University of Colorado.

\begin{abstract}
Apparatus
Each subject was seated $60 \mathrm{~cm}$ in front of a 60 -cm-wide $x$ 60 -cm-high panel which was covered with black felt cloth. At approximately eye level, a $2.7-\mathrm{cm}$-diam aperture was present. The subjects viewed a disk of white light projected onto a translucent glass screen behind the aperture. The light source consisted of a Light Discrimination Apparatus manufactured by the Lafayette Instrument Company (Model 14011), using a 60-W Sylvania clear Decor Lite (60CA9C/BL). Eleven different light intensities were selected so as to be $.188 \mathrm{log}$ units apart. The intensity values and their experimental designations were: stimulus (SV)1, $0.831 \mathrm{fL}$; SV2, $1.28 \mathrm{fL}$; SV3, $1.97 \mathrm{fL}$; SV4, $3.04 \mathrm{fL}$; SV5, $4.69 \mathrm{fL}$; SV6, $7.23 \mathrm{fL}$; SV7, $11.2 \mathrm{fL}$; SV8, $17.2 \mathrm{fL}$; SV9, $26.5 \mathrm{fL}$; SV10, $40.9 \mathrm{fL}$; SV11, 63.0 fL. The experiment was conducted in a small, dimly illuminated room. The light reflected from the disk when it was not illuminated was approximately $.01 \mathrm{fL}$.
\end{abstract}

\section{Procedure}

The male subjects and female subjects were unsystematically assigned to 2 major groups (rating or same-different) and to one of three preexposure conditions [preexpose bright, preexpose dim, or control (no preexposure)]. Each of these 12 groups was further subdivided into 2 groups (TS4 or TS8). A complete designation of groups and stimuli is provided in Table 1.

After the subject was seated in front of the stimulus panel, the following instructions were read to both preexpose bright and preexpose dim subjects: "This is an experiment in bright-

Table 1

Summary of Experimental Conditions

\begin{tabular}{|c|c|c|c|c|c|c|}
\hline & \multicolumn{2}{|c|}{$\begin{array}{c}\text { Preexpose Dim } \\
\text { (Preexpose SV1, 2, 3) }\end{array}$} & \multicolumn{2}{|c|}{$\begin{array}{c}\text { Preexpose Bright } \\
\text { (Preexpose SV9,10,11) }\end{array}$} & \multicolumn{2}{|c|}{$\begin{array}{c}\text { Control Group } \\
\text { (No Preexposure) }\end{array}$} \\
\hline & $\mathrm{TS}=\mathrm{SV} 4$ & $\mathrm{TS}=\mathrm{SV} 8$ & $\mathrm{TS}=\mathrm{SV} 4$ & $\mathrm{TS}=\mathrm{SV} 8$ & $\mathrm{TS}=\mathrm{SV} 4$ & $\mathrm{TS}=\mathrm{SV} 8$ \\
\hline \multicolumn{7}{|l|}{ Rating } \\
\hline Male & 10 & 10 & 10 & 10 & 10 & 10 \\
\hline Female & 10 & 10 & 10 & 10 & 10 & 10 \\
\hline \multicolumn{7}{|c|}{ Same-Different } \\
\hline Male & 10 & 10 & 10 & 10 & 10 & 10 \\
\hline Female & 10 & 10 & 10 & 10 & 10 & 10 \\
\hline
\end{tabular}

Note-Entries indicate number of subjects in each group. Test stimuli for all subjects: SV4, 5, 6, 7, 8. 
ness perception. A light will be presented repeatedly through a small hole in the screen in front of you. Each time it will be presented for five seconds and may have a different brightness. The first brightness is called the test brightness. Try to remember this brightness because you will have to distinguish it from all the other brightnesses. When you do recognize the test brightness, say 'same." If a subsequent brightness is different from the test brightness, say 'different.' Remember, each time the light is presented it will stay on for only five seconds, so try to respond while the light is on. The first light is the test brightness. Keep its brightness in mind. For every light after that, say only 'same' or 'different.' Any questions?"'

Only questions dealing with the procedure were answered by the experimenter. Following any needed clarifications of instructions, the preexposure dim groups were shown SV2 and the preexpose bright groups were shown SV10. Each subject was then shown five series of three stimuli (i.e., 15 presentations). The three stimuli were SV1, 2, 3 for the preexpose dim group and SV9, 10, 11 for the preexpose bright group. The stimuli were randomized within each series and the intertrial interval ranged unsystematically from 3 to $6 \mathrm{sec}$. Then the following instructions were given to the rating groups: "That was the end of the first task. Your second task will be to rate the brightness of the light. Each time the light is presented, give me a number from one to seven that represents how bright the light seems to you. Let one stand for very dim, seven for very bright and four for a medium brightness. Remember, each time the light is presented it will stay on for only five seconds, so try to respond while the light is on, using a number from one to seven, with numbers less than four representing lights that seem dim, numbers above four representing lights that seem bright, and numbers around four representing lights that seem to have a medium brightness. Any questions?" And the following instructions were given to the same-different groups: "That was the end of the first series. The next light will be the new test brightness. Keep its brightness in mind. For every light after that, say 'same' or 'different.' ",
The training stimulus (TS) was then presented for $5 \mathrm{sec}$. One group of subjects from each condition was shown a TS of SV4, and the other group was shown a TS of SV8. Starting approximately $5 \mathrm{sec}$ after the training stimulus presentation, six test series of five stimuli (SV4, 5, 6, 7, 8) were presented. For each subject, the test stimuli were randomized within each test series. Stimuli were presented for $5 \mathrm{sec}$ each and the intertrial interval ranges unsystematically from 3 to $6 \mathrm{sec}$.

For control groups of subjects, the preexposure phase of the experiment was omitted. The experiment started with the TS exposure, and the instructions were modified accordingly.

\section{RESULTS AND DISCUSSION}

A gradient of stimulus generalization was constructed for each same-different subject; data for the generalization gradients consisted of the number of "same" responses made to each of the test stimuli. The mean of these gradients (mean stimulus to which a subject said "same") was used as a measure of central tendency reflecting the locus of maximal generalized responding (cf. Thomas, 1962). A gradient was similarly constructed for each rating subject; the rating gradient consisted of the number of " 4 " responses made to each of the test stimuli. For every rating subject, AL was defined as the mean of his rating gradient (mean stimulus rated " 4 ") in order that the "same" and rating measures be as comparable as possible. ${ }^{1}$ For both the same-different and rating groups, each subject yielded a score (the mean stimulus called "same" or the mean

Table 2

Mean TS Rating (Column 1) and Series AL (Column 3) for the Rating Groups, Mean Stimulus "Same" (Column 4) for the Same-Different Groups, and Estimates of X (Columns 2 and 5)

\begin{tabular}{|c|c|c|c|c|c|c|}
\hline \multirow[b]{2}{*}{ Preexposure } & & \multirow[b]{2}{*}{ TS Rating } & \multirow[b]{2}{*}{ Columns 1-“4" } & \multirow[b]{2}{*}{ Series AL } & \multirow{2}{*}{$\frac{4}{\begin{array}{c}\text { Mean Stimulus } \\
\text { "Same" }\end{array}}$} & \multirow{2}{*}{ 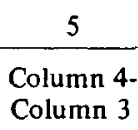 } \\
\hline & & & & & & \\
\hline Dim & $\begin{array}{l}\text { Male } \\
\text { Female } \\
\text { Mean }\end{array}$ & $\begin{array}{l}4.20 \\
4.10 \\
4.15\end{array}$ & $\begin{array}{l}.20 \\
.10\end{array}$ & $\begin{array}{l}\text { TS } 4 \\
6.02 \\
6.04 \\
6.03\end{array}$ & $\begin{array}{l}6.38 \\
6.11 \\
6.25\end{array}$ & $\begin{array}{l}.36 \\
.07\end{array}$ \\
\hline None (Control) & $\begin{array}{l}\text { Male } \\
\text { Female } \\
\text { Mean }\end{array}$ & $\begin{array}{l}3.30 \\
3.90 \\
3.60\end{array}$ & $\begin{array}{l}-.70 \\
-.10\end{array}$ & $\begin{array}{l}6.34 \\
6.63 \\
6.49\end{array}$ & $\begin{array}{l}6.10 \\
5.42 \\
5.76\end{array}$ & $\begin{array}{l}-.24 \\
-1.21\end{array}$ \\
\hline Bright & $\begin{array}{l}\text { Male } \\
\text { Female } \\
\text { Mean }\end{array}$ & $\begin{array}{l}1.70 \\
1.60 \\
1.65\end{array}$ & $\begin{array}{l}-2.30 \\
-2.40\end{array}$ & $\begin{array}{l}6.61 \\
6.78 \\
6.70\end{array}$ & $\begin{array}{l}4.81 \\
4.86 \\
4.84\end{array}$ & $\begin{array}{l}-1.80 \\
-1.92\end{array}$ \\
\hline Dim & $\begin{array}{l}\text { Male } \\
\text { Female } \\
\text { Mean }\end{array}$ & $\begin{array}{l}5.60 \\
5.60 \\
5.60\end{array}$ & $\begin{array}{l}1.60 \\
1.60\end{array}$ & $\begin{array}{l}T S 8 \\
5.75 \\
5.83 \\
5.79\end{array}$ & $\begin{array}{l}7.29 \\
7.02 \\
7.16\end{array}$ & $\begin{array}{l}1.54 \\
1.19\end{array}$ \\
\hline None (Control) & $\begin{array}{l}\text { Male } \\
\text { Female } \\
\text { Mean }\end{array}$ & $\begin{array}{l}3.50 \\
3.70 \\
3.60\end{array}$ & $\begin{array}{l}-.50 \\
-.30\end{array}$ & $\begin{array}{l}6.67 \\
6.24 \\
6.46\end{array}$ & $\begin{array}{l}6.64 \\
6.73 \\
6.69\end{array}$ & $\begin{array}{r}-.03 \\
.49\end{array}$ \\
\hline Bright & $\begin{array}{l}\text { Male } \\
\text { Female } \\
\text { Mean }\end{array}$ & $\begin{array}{l}3.20 \\
2.60 \\
2.40\end{array}$ & $\begin{array}{l}-.80 \\
-1.40\end{array}$ & $\begin{array}{l}6.84 \\
6.56 \\
6.70\end{array}$ & $\begin{array}{l}6.16 \\
6.09 \\
6.13\end{array}$ & $\begin{array}{l}-.68 \\
-.47\end{array}$ \\
\hline
\end{tabular}

Note-Mean stimulus "same" refers to the mean of the generalization gradients for the same-different groups. See text for explanation of estimates of $\boldsymbol{X}$. 
stimulus rated "4") and each group was then characterized by the mean of the distribution of gradient means.

Table 2 presents the TS ratings, series ALs and means of the generalization gradients of all groups in this experiment. It is clear from the table that there are no consistent or sizable differences attributable to sex of subject, and in the description that follows the data are pooled across sex.

The predicted effects of dim preexposure and bright preexposure are to produce low and high preexperimental ALs, respectively. These ALs are to be reflected in differences in the initial rating of the TS values. If the preexperimental AL is slightly below a TS = SV4, for example, that TS should be rated as slightly brighter than AL ("4"). Similarly, if the preexperimental AL is greatly above the TS value of SV4, the TS should receive a very low rating. If the control subjects have a preexperimental $\mathrm{AL}$ between these two extremes or accept the TS as AL, then their ratings should be intermediate to those of the two preexposure groups. Note that this is exactly what happened. The control subjects rated the TS4 as 3.60. Those subjects with a dim preexposure rated this TS as 4.15 , i.e., 0.55 units brighter than the control group did, whereas subjects preexposed to bright lights rated the TS as 1.65 , i.e., 1.95 units dimmer than the control. Thus both the directions and relative magnitudes of the differences between control and preexposure subjects' TS ratings are in accord with prediction, as are those of the subjects exposed to TS8 (see Table 2). An analysis of variance yielded significant effects on rating of the TS of preexposure condition $[\mathrm{F}(2,108)=59.17$, $\mathrm{p}<.01]$ for TS $=$ SV4 vs. TS $=$ SV8 $[\mathrm{F}(1,108)=$ $21.27, \mathrm{p}<.01]$, and for the interaction between preexposure and TS condition $[F(2,108)=5.40$, $\mathrm{p}<.01]$. No other effects were significant.

The series AL for the TS4 controls was 6.49 and for the TS 8 controls, 6.46 , or a little brighter than the center of the series, which agrees with the finding of Thomas, Svinicki and Vogt (1973) for a similar series of brightnesses. Although the AL for each preexposed group should converge on the AL of the control group, when averaged over the entire test the AL should show the effect of the preexposure, and this is true for every group (Table 2). Note that for the TS4 subjects, the series AL was 6.04 with dim preexposure, 6.49 with no preexposure, and 6.70 with bright preexposure. The series $A L$ values were also ordered as predicted in the TS8 groups. The effect on AL of preexposure was significant $[F(2,108)=12.81, p<.01]$, and there was no effect on AL for TS condition $(\mathrm{F}<1.0)$.

Having established that the preexposure conditions were successful in manipulating "preexperimental" ALs, it is necessary next to demonstrate that the central tendency shifts did indeed occur in the same-

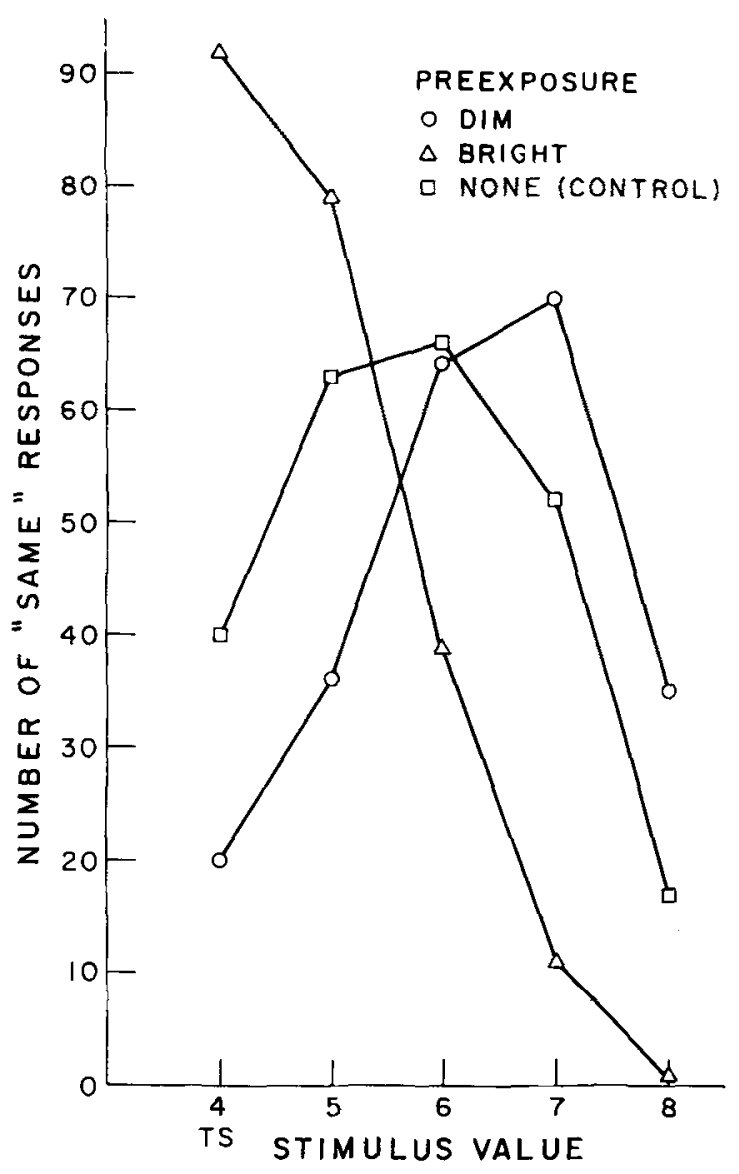

Figure 1. Mean generalization gradients for the three groups for which TS $=$ SV4.

different groups and that they occurred in parallel fashion to the $\mathrm{AL}$ changes. Figure 1 shows the generalization gradients for the same-different groups which received TS4, collapsed across sex. Only the preexposed bright group which would have encoded the TS as "very dim" failed to show a shift, which is in accord with AL prediction. For the control group, the peak of responding is at the center of the series (SV6), and for the preexposed dim group, which would have encoded the TS as "slightly bright," a shift to a brighter value (SV7) than the series $A L$ and brighter than that in the control group occurs, as predicted. For the TS8 groups (Figure 2), all show a central tendency shift, with the preexposed dim group this time showing the least shift, the control group a little more, and the preexposed bright group shifting beyond the series $A L$ to SV6.

For purposes of statistical analysis of the locus of maximal responding in the different groups, the gradient mean measure was used. An analysis of variance of the group means of these individual gradient mean values shows significant effects for preexposure condition $[\mathrm{F}(2,108)=43.60, \mathrm{p}<.01]$ and for TS value $[\mathrm{F}(1,108)=84.53, \mathrm{p}<.01]$. No 


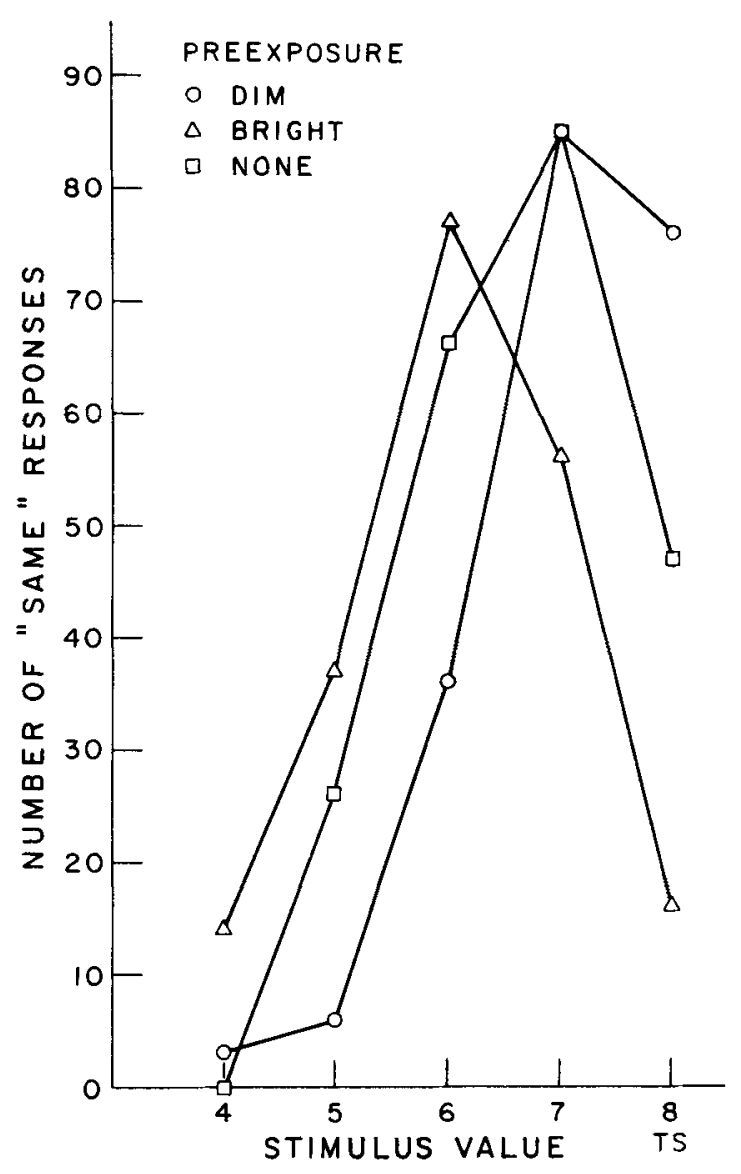

Figure 2. Mean generalization gradients for the three groups for which TS $=$ SV8.

other effects were significant.

Having demonstrated that in each case the preexposure was sufficient to affect both the AL and central tendency, it now remains to show that these effects are parallel. To accomplish this, the gradient mean and the $A L$ values were again used. If subjects in the same-different groups encoded TS as $\mathrm{AL} \pm \mathrm{X}, \mathrm{X}$ should be proportional to the difference between the TS rating and " 4 " (the median rating) (Table 2 , Column 2 ). If the shift during testing in ratings (AL) is parallel to the shift in "same" judgments, the difference between the mean of the generalization gradient and the series AL (Table 2, Column 5) should also be proportional to $\mathrm{X}$. The correlation between these two estimates of $X$ is a test of the hypothesis that $A L$ shift and the central tendency shift occurs in parallel. The correlation coefficient $(r)$ between these two differences is $+\mathbf{0 . 8 2 4}$ and is highly significant $[\mathrm{t}(10)=4.60, \mathrm{p}<.01]$. Thus we have demonstrated that, across groups, AL changes and central tendency shifts occur proportionally.

We have shown that "preexperimental" experience with stimuli can affect the central tendency shift as well as AL judgments and that these effects are parallel in magnitude and direction. This lends support to the Capehart et al. (1969) proposal that $\mathrm{AL}$ mediates the central tendency effect. It also lends support to the further proposal by Thomas et al (1974) that the TS need not always be encoded as AL. (Indeed, in this experiment, as in that of Thomas et al., subjects with no preexposure rated the TS slightly below the medium rating.)

Since the systematically changing ratings of the test stimuli parallel changes in the locus of generalization (recognition) responses, it is appropriate to consider an alternative view of the basis for such changes in stimulus ratings. As pointed out earlier, the AL theory of stimulus generalization defines $\mathrm{AL}$ empirically, as the "average" stimulus, rather than theoretically, as for example a weighted log mean (Helson, 1947, 1964). Parducci $(1963,1965)$ has presented data critical of the log mean formulation. $\mathrm{He}$ has shown that in certain situations the empirical AL varies directly with both the midpoint (mean of the two extreme stimuli) and median of the distributions presented for judgment but not with the mean. The judgments (ratings) then represent a compromise between the tendency to divide the range of stimuli into proportionate subranges and the tendency to use different parts of the response scale with proportionate frequencies. In the present experiment, mean and median, as well as range of the test series, vary together so it is not possible to attribute the shift in this experiment to any one alone. However, in the case of generalization (recognition) responses, no shift is required to use the responses "same" and "different" in a particular proportion, nor, in fact, is there any change in the proportion of "same" responses when the shift is large vs. small. Therefore, if Parducci's rangefrequency compromise is to apply to the central tendency effect, we must assume that the range of stimuli is broken into (internal) subranges which are related proportionally both to the entire range and to the stimulus spacing rather than to the response scale. This would then permit both the central tendency effect and the shift in rating responses. This internal compromise, rather than an external compromise, may underlie Parducci's (1963) failure to find an effect in his category rating studies either for different rating methods or for allowing subjects to see how often they had used particular rating categories.

It is, of course, possible to conceptualize these experimental manipulations without reference to AL. It could be argued that preexposure to dim lights raised the subrange into which TS was placed from, say, 4 to 8 . Then subsequent testing with a series asymmetrically spaced around the TS produced a shift in the values of physical stimuli which were categorized as being in subrange 8 , thereby producing a shift in the generalization (recognition) 
gradient. The encoding of TS as simply in subrange 8 would seem more straightforward than encoding it as $\mathrm{AL}+4$, but the $\mathrm{AL}$ formulation has the advantage that the contextual frame of reference is treated as a single value rather than an entire distribution of experienced stimuli. While the adaptation level model has a provision for the role of residual stimuli from past experience, the range-frequency model, in its present form, does not. For this reason, it would seem appropriate to continue to conceive of the effect of a frame of reference in AL terms and to view rating measures and same-different responses as different behavioral manifestations of this effect.

\section{REFERENCES}

Capehart. J.. Tempone, V. J., \& Hébert, J. A. A theory of stimulus equivalence. Psychological Review, 1969, 76, 405-418.

Givrintano, L. P. Stimulus generalization in humans and pigeons as a function of training and test stimulus parameters. Unpublished doctoral dissertation, University of Colorado. 1972.

Hé Bert, J. A., Bullock, M., Levitt, L., WoOdW ARD, K. G., \& MCGuirk. F. D. Context and frequency effects in the generalization of a human voluntary response. Journal of Experimental Psychology, 1974, 102, 456-462.

Hébert, J. A., Origlio, D. P., \& McGuirk, F. P., III. Training and testing effects in the generalization of a voluntary response. Psychonomic Science, 1972, 26. 209-210.

HeLson, H. Adaptation-level as a frame of reference for prediction of psychophysical data. American Journal of Psychology. 1947. 60, 1-29.

Helson. H. Adaptation level theory. New York: Harper \& Row, 1964.

Helson. H. \& Avant, L. L. Stimulus generalization as a function of contextual stimuli. Journal of Experimental Psychology, 1967, 73. 565-567.

Parducci. A. Range-frequency compromise in judgment. Psychological Monographs, 1963, 77, No. 2.
Parducci, A. Category judgment: A range-frequency model. Psychological Revien: 1965, 72, 407-418.

Tномаs. D. R. The effects of drive and discrimination training on stimulus generalization. Journal of Experimental Psychology, $1962,64,24-28$.

Thomas. D. $R$. The role of adaptation-level in stimulus generalization. In G. Bower (Ed.), The psychology of leaming and motivation (Vol. 8). New York: Academic Press, 1974.

Thomas, D. R., \& Fenner, D. P. The central tendency effect in stimulus generalization: The effect of sex of subject. American Journal of Psychology, 1978, in press.

Thomas, D. R., \& Jones, C. G. Stimulus generalization as a function of the frame of reference. Journal of Experimental Psychology, 1962, 67, 77-80.

Thomas, D. R., Strub, H., \& Dickson, J. F., JR. Adaptationlevel and the central tendency effect in stimulus generalization. Journal of Experimental Psychology, 1974, 103, 446-474.

Thomas, D. R., Svinicki, M. D., \& Vogt, J. Adaptation level as a factor in human discrimination learning and stimulus generalization. Journal of Experimental Psychology, 1973, 97. 210-219.

Thоmas, D. R., \& Tномas, D. H. Stimulus labeling, adaptation level, and the central tendency shift. Journal of Experimental Psychology, 1974, 103, 896-899.

NOTE

1. AL was also determined for each rating-group subject by linearly regressing stimulus value on rating and taking $\mathrm{AL}$ as the stimulus value corresponding to a rating of "4." The two measures of AL were positively correlated with $r=.87[\mathrm{t}(108)=$ $19.00, p<.01]$. Identical analyses of variance were performed on both measures of $\mathrm{AL}$ : although only the results of $\mathrm{AL}$ as the mean stimulus rated "4" are reported here, all significant effects were significant using either measure of $\mathrm{AL}$ and all nonsignificant effects were nonsignificant for both measures. Our choice of AL as the mean stimulus rated "4" was made because of its procedural comparability to the response "same" in the "same-different" groups.

(Received for publication February 14, 1978; revision accepted May 19, 1978.) 